\title{
História e marco legal de um projeto de assentamento agroextrativista na Amazônia Oriental, Brasil
}

\section{History and legal framework of an agroextractive settlement project in Eastern Amazonia, Brazil}

\author{
Historia y marco legal de un proyecto de asentamiento \\ agroextractivista en la Amazonia Oriental, Brasil
}

\author{
Valdecy dos Anjos da Silva ${ }^{1}$ \\ Alanna do Socorro Lima da Silva² \\ Helionora da Silva Alves ${ }^{3}$ \\ Thiago Almeida Vieira ${ }^{4}$
}

\begin{abstract}
${ }^{1}$ Mestre em Sociedade, Ambiente e Qualidade de Vida pela Universidade Federal do Oeste do Pará (PPGSAQ/UFOPA). Especialista em Educação Ambiental voltada à Prática Escolar pelo Instituto de Pós-Graduação e Extensão (IBPEX). Bacharel em Direito pela UFOPA e em Turismo pela Universidade Federal do Pará (UFPA). Atualmente, desenvolve a função pública de Técnica em Gestão de Meio Ambiente, na Secretaria de Estado de Meio Ambiente e Sustentabilidade do

Pará. E-mail: valdecydosanjos@hotmail.com, ORCID: https://orcid.org/0000-0003-3183-2259
\end{abstract}

${ }^{2}$ Doutora e mestre em Medicina Veterinária pela Universidade Estadual Paulista Júlio de Mesquita Filho (UNESP). Médica-veterinária pela Universidade Federal Rural da Amazônia (UFRA). Atualmente, é pesquisadora do Projeto Bio-Fauna da UFRA. Professora adjunta da Universidade Federal do Oeste do Pará (UFOPA), docente nos cursos de Bacharelado em Zootecnia e Ciências Agrárias. Está como Diretora do Instituto de Biodiversidade e Florestas (IBEF/UFOPA). É também professora permanente do Mestrado do Programa de Pós-Graduação em Sociedade, Ambiente e Qualidade de Vida (PPGSAQ) da UFOPA. E-mail: alanna.silva@ufopa.edu.br, ORCID: https://orcid.org/0000-0003-2568-4288

\footnotetext{
${ }^{3}$ Doutora e mestre em Agricultura Tropical pela Universidade Federal de Mato Grosso (UFMT); engenheira agrônoma também pela UFMT. Professora associada I da Universidade Federal do Oeste do Pará (UFOPA), docente nos cursos de Bacharelado em Agronomia, Engenharia Florestal, Zootecnia e Ciências Agrárias. É também professora permanente do Programa de Pós-Graduação em Sociedade, Ambiente e Qualidade de Vida (PPGSAQ) da UFOPA.E-mail: helionora.alves@ufopa.edu.br, ORCID: https://orcid.org/0000-0003-2118-5502
}

4 Pós-doutor pelo Research Centre for Tourism, Sustainability and Well-Being (CinTurs) da Universidade do Algarve (UAlg). Doutor em Ciências Agrárias, mestre em Ciências Florestais e engenheiro florestal pela Universidade Federal Rural da Amazônia (UFRA). Professor associado

I da Universidade Federal do Oeste do Pará (UFOPA), docente nos cursos de Bacharelado em Agronomia, Engenharia Florestal e Ciências Agrárias. É também professor permanente do Programa de Pós-Graduação em Sociedade, Ambiente e Qualidade de Vida (PPGSAQ) e do Doutorado em Sociedade, Natureza e Desenvolvimento (PPGSND) da UFOPA. E-mail: thiago.vieira@ufopa.edu.br, ORCID: https://orcid.org/0000-0001-9926-2606 
Resumo: Este artigo discute sobre o surgimento da Região do Eixo Forte e sua caminhada até se tornar Projeto de Assentamento Agroextrativista na área rural do município de Santarém, Amazônia brasileira, com o objetivo de descrever como se deu seu processo de criação, contextualizando com o marco legal brasileiro e enfatizando, ainda, a contribuição do assentamento para função socioambiental da terra. A metodologia utilizada foi apoiada por levantamento bibliográfico e pesquisa documental. Assim, espera-se que este estudo possa contribuir para o conhecimento sobre a região do Eixo Forte, até a criação do assentamento e seus aspectos de construção legal, servindo de registro científico da história de organização dos assentados para a criação e proteção dessas terras.

Palavras-chave: conservação ambiental; extrativismo; função social da propriedade; reforma agrária; Brasil.

\begin{abstract}
This paper deals with the emergence of the Eixo Forte region and its journey towards becoming an Agroextractive Settlement Project in rural Santarém, Brazilian Amazon, to describe how its creation process took place, contextualizing with the Brazilian legal framework while emphasizing the contribution of this settlement for the socioenvironmental function of the land. The methodology used was supported by a bibliographic survey and documentary research. Thus, it is hoped that this study can contribute to the knowledge of the Eixo Forte region until the establishment of the settlement and its aspects of legal construction, serving as a scientific record of the history of the organization of settlers for the creation and protection of these lands.
\end{abstract}

Keywords: environmental conservation; extractivism; social function of the land; agrarian reform; Brazil.

Resumen: Este artículo analiza el surgimiento de la Región Eixo Forte y su viaje para convertirse en un Proyecto de Asentamiento Agroextractivo en el área rural en el municipio de Santarém, Amazonia brasileña, con el objetivo de describir cómo se llevó a cabo su proceso de creación, contextualizándolo con el marco legal brasileño y enfatizando la contribución del asentamiento a la función socioambiental de la tierra. La metodología utilizada fue apoyada por la encuesta bibliográfica y la investigación documental. Por lo tanto, se espera que este estudio pueda contribuir al conocimiento sobre la región de Eixo Forte, hasta el establecimiento del asentamiento y sus aspectos de construcción legal, sirviendo como un registro científico de la historia de la organización de los colonos para la creación y protección de estas tierras.

Palabras clave: conservación del medio ambiente; extractivismo; función social de propiedad; reforma agraria; Brasil. 


\section{INTRODUÇÃO}

Na década de 1960, foi fundada a cidade de Santarém, localizada na região oeste do estado do Pará, Amazônia Oriental; mais especificamente, na área de influência do Rio Tapajós. Nesse período, o meio rural da região era caracterizado por pequenos povoados, em que as pessoas viviam da pesca, caça, extrativismo vegetal e agricultura de subsistência. Até meados do século XX, deu-se o povoamento ao longo das margens do Rio Tapajós até a altura da vila de Alter do Chão, e muitas comunidades foram surgindo, movimentadas pelas águas límpidas e navegáveis do conhecido Igarapé Açu.

A região vivenciou uma estratégia de conservação ambiental e, também, da cultura dos povos locais, com a criação de áreas protegidas e assentamentos da reforma agrária. A história de ocupação da vila Alter do Chão foi importante no processo de criação da Área de Proteção Ambiental Alter do Chão e do Projeto de Assentamento Agroextrativista do Eixo Forte, o que, paulatinamente, viabilizou a fundação de novas comunidades, devido à instalação de infraestruturas para a região, como a estrada de ligação da sede urbana de Santarém a essa vila. Contexto este que é resultado de muitas lutas dos moradores e das lideranças comunitárias, de organizações dos moradores que entendiam que somente organizados conseguiriam melhorias para as localidades em que viviam.

Essa modalidade de assentamento agroextrativista é reconhecida por destinar às populações tradicionais, tais como seringueiros, coletores de castanha e de coco babaçu, balateiros, coletores de sementes, fibras e outros, a oportunidade de desenvolver atividades baseadas no extrativismo vegetal e animal, amparadas nas premissas do desenvolvimento sustentável. Pelo exposto, objetivou-se analisar o processo de criação dessa modalidade de assentamento diferenciado, contextualizando os aspectos jurídicos e enfatizando a função socioambiental do imóvel rural, a partir do caso do Projeto de Assentamento Agroextrativista (PAE) Eixo Forte, Santarém, Brasil.

\section{METODOLOGIA}

O assentamento estudado é denominado PAE Eixo Forte, e sua área territorial é de aproximadamente 12.689 hectares, formada por 16 
comunidades tradicionais de populações que já vivam e moravam na área, há gerações (EMATER, 2008). Até 2017, abrigava 1.385 famílias assentadas, segundo a Relação de Beneficiários do Instituto Nacional de Colonização e Reforma Agrária (INCRA, 2017). O assentamento está localizado a três quilômetros de distância do município de Santarém, na Amazônia Oriental, Brasil (Figura 1). Possui acesso rodoviário facilitado e acesso fluvial pelo Rio Tapajós. Internamente, tem malha hídrica caracterizada por igarapés, fontes e nascentes. Apresenta áreas de floresta ombrófila e de savanas amazônicas.

Quanto aos procedimentos metodológicos, trata-se de uma pesquisa descritiva, a qual se iniciou por uma pesquisa bibliográfica, por meio de consultas realizadas na literatura correlata ao tema da pesquisa, com posterior análise das obras (REIS, 2012; GERHARDT; SILVEIRA, 2009). Posteriormente, recorreu-se à pesquisa documental, por meio da análise de documentos, a fim de obter informações, dados e fatos históricos relatados em documentos informativos e institucionais (oficiais), incluindo dados estatísticos (GERHARDT; SILVEIRA, 2009; SÁ-SILVA; ALMEIDA; GUINDANI, 2009). Foram consultadas também as bases da legislação brasileira relacionadas à reforma e colonização agrária e ambiental. 


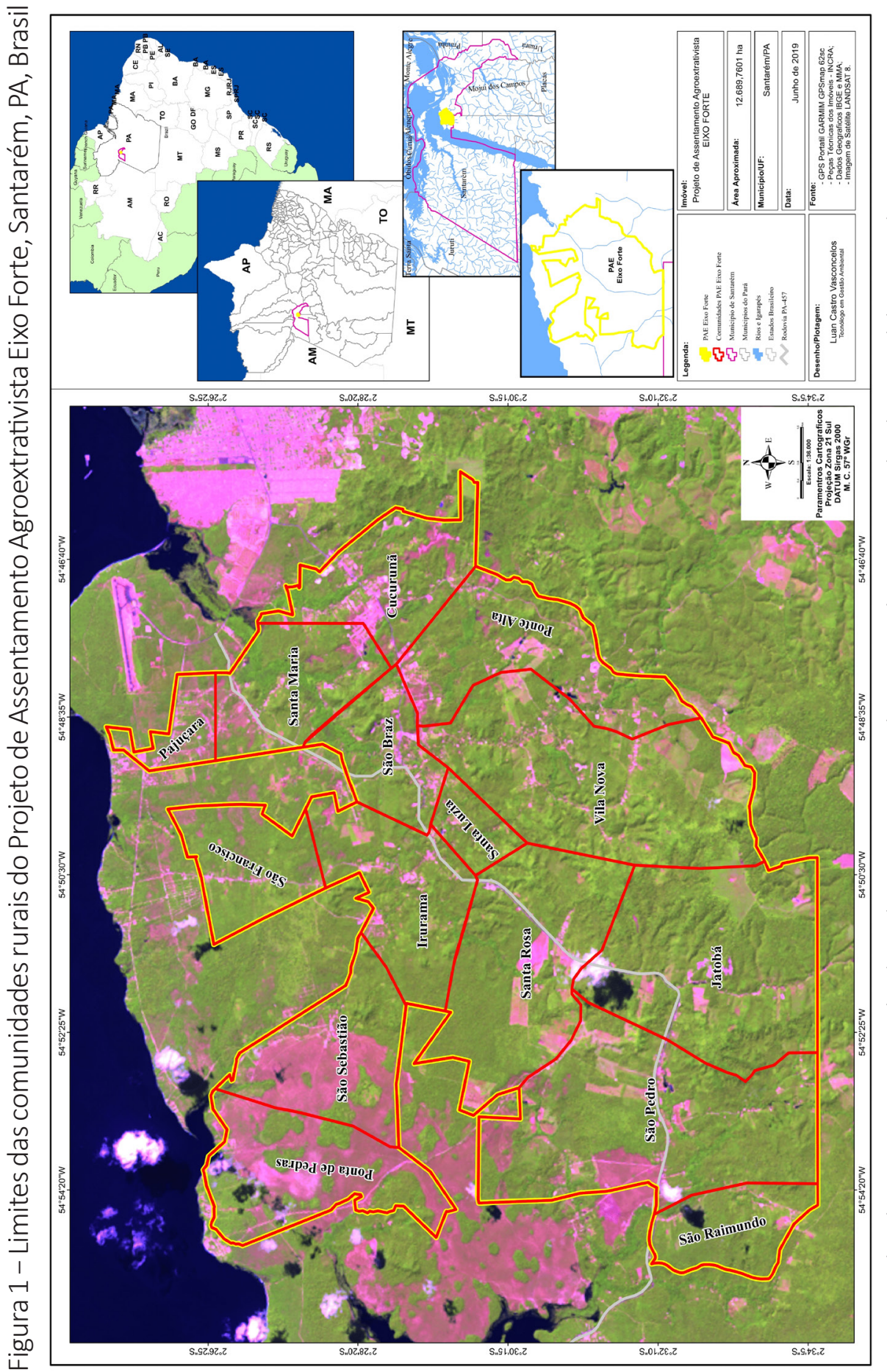

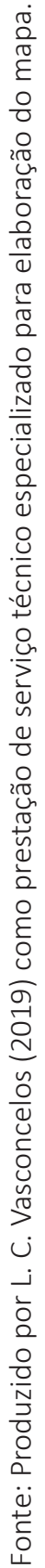




\section{RESULTADOS E DISCUSSÃO}

\subsection{Um breve histórico do Eixo Forte e do assentamento}

O surgimento da região do Eixo Forte tem forte ligação com a história de Alter do Chão, desde sua fundação. Machado (1989) mostrou que, no século XVII, ocorreu o chamado "primeiro sistema de controle territorial", com a construção de fortins nos lugares onde havia populações indígenas, com intuito de capturá-los, controlá-los e pacificá-los, usando as companhias religiosas para isso. Para essa autora, na divisão desses "territórios das missões" entre as ordens regulamentadas pela Coroa, a ordem dos jesuítas ficou com o sul do Rio Amazonas até a fronteira com as possessões espanholas, abrangendo os rios Tocantins, Xingu, Tapajós e Madeira; a ordem dos franciscanos da Piedade ficou com a margem esquerda do Baixo Amazonas; e a dos franciscanos de Santo Antônio, com as missões do Baixo Amazonas.

Conforme Tavares (2008), no Vale do Amazonas a missão dos jesuítas foi a mais poderosa, pois tinha o poder de gestão da mão de obra indígena escrava. Então, foram fundadas, no século XVII, 62 freguesias durante a política pombalina, algumas delas criadas a partir das missões, e outras de aldeias administradas pelos missionários, entre as missões que passaram a ser vilas com denominações portuguesas, por ordem de Mendonça Furtado (BARBOSA, 1976).

Rente (2006) destacou que, bem antes da elevação à categoria de vila, Alter do Chão teve como primeiros habitantes os índios da tribo dos Boraris, que habitavam a região do Tapajós. A autora apontou ainda que, após 196 anos, Alter do Chão passou então da condição de vila à elevação de distrito, sendo regulamentada pela Lei Estadual n. 158, de 31 de dezembro de 1948, recebendo a denominação de Distrito de Alter do Chão, como um dos cinco distritos que compunham o município de Santarém. Esse distrito está situado à margem direita do Rio Tapajós e distante cerca de $30 \mathrm{~km}$ de Santarém, com acesso fluvial pelo Rio Tapajós e terrestre por meio da Rodovia Everaldo Martins PA-457.

Em meados do século XX, como não era indicado um vigário para a região de Alter do Chão, integrantes ativos dos movimentos de catequese resolveram se reunir sozinhos para planejarem as ações de melhorias para 
Alter do Chão e outras comunidades da região, como os puxiruns (mutirões), realizados para limpeza de pequenas estradas (ramais), construção de barracões, pontes sobre os recursos hídricos etc. (SANTOS, 2018). Penteado (2013) relatou que a união dessas pessoas em prol da região acabou por influenciar no seu nome: Eixo Forte; em que "Eixo" marca a mudança da via de deslocamento fluvial para terrestre, com a abertura da PA-457, e o termo Forte (Força) reafirma a união das comunidades em prol dos interesses comuns.

Em 1980, duas novas comunidades passam a integrar a região do Eixo Forte: Santa Luzia e Santa Maria. Em 1984, foram fundadas as comunidades Santa Rosa II, São Pedro, São Raimundo e Caranazal. Em 1987, o Frei Edilberto Sena passou a ser vigário na região e teve um papel fundamental nas organizações das comunidades, incentivando o movimento. Em 1ㅇ de maio de 1989, na comemoração de nove anos de Eixo Forte, foi registrada formalmente como pessoa jurídica a Associação de Moradores do Eixo Forte (AMEIFOR), tendo então 20 comunidades como integrantes, as quais foram, à época: Alter do Chão, a mais antiga; Juá; Pajuçara; Irurama (1932); São Braz (1933); Jatobá (1940), Andirobalzinho (1940); Santa Rosa I (1950); Cucurunã (1952); Ponta de Pedras (1960); São Sebastião (1960); Ponte Alta (1967); Vila Nova (1972); São Francisco de Carapanari (1975); Santa Maria (1980); Santa Luzia (1980); Santa Rosa II (1984); São Pedro (1984); São Raimundo (1984) e Caranazal (1984) (SANTOS, 2018). A região, ainda na década de 1980, recebeu energia elétrica distribuída pela companhia estatal da época e também teve sua principal estrada de ligação asfaltada. Isso pode ter aumentado o interesse de pessoas de fora do Eixo Forte em ocupar áreas dessa região.

Em 2003, a Prefeitura Municipal de Santarém criou a Área de Proteção Ambiental (APA) Alter do Chão, Lei n. 17.771/2003, de 2 de julho de 2003, estratégia pública de conservação ambiental desse território em forma de Unidade de Conservação de Uso Sustentável (SANTARÉM, 2003), mas diferenciada em questões de uso do território, haja vista que, de acordo com Brasil (2000), uma APA apresenta “[...] certo grau de ocupação humana, dotada de atributos [...] importantes para a qualidade de vida e o bem-estar das populações humanas, e tem como objetivos básicos proteger 
a diversidade biológica, disciplinar o processo de ocupação e assegurar a sustentabilidade do uso dos recursos naturais".

Entre os anos de 2004 e 2005, o Sindicato dos Trabalhadores e Trabalhadoras Rurais (STTR) tomou a iniciativa de chamar as lideranças comunitárias do Eixo Forte para tomarem providências a respeito da especulação sobre avanço da soja na cidade, evitando que moradores perdessem suas áreas. Foi encaminhada ao INCRA a proposta de transformar a área em um assentamento agroextrativista, como forma de garantir a posse da terra (EMATER, 2008). Assim, sobreposta em parte à área da APA, em 2005 foi criado o Projeto de Assentamento Agroextrativista (PAE) do Eixo Forte (INCRA, 2005a). O Assentamento, fruto de mobilizações e reinvindicações de parte dos líderes comunitários de dezesseis comunidades envolvidas, foi criado com área de aproximadamente $12.689,00$ ha, com as comunidades distribuídas principalmente às margens ou proximidades da rodovia PA-457 e às margens do Rio Tapajós (EMATER, 2008).

Em 2017, atendia uma demanda de 1.385 famílias cadastradas pelo (INCRA, 2017), contudo, ainda abaixo da capacidade do assentamento prevista na portaria de sua criação. Essa modalidade de assentamento destina-se às populações tradicionais, as quais baseiam o uso dessas terras sob a égide do desenvolvimento sustentável, sendo atividades economicamente viáveis, socialmente justas e ecologicamente sustentáveis (PUREZA, 2017). Diferentemente de outras modalidades de assentamentos agrários, como o Projeto de Assentamento (PA), tradicional e/ou convencional, em que ocorre o deslocamento de pessoas para espaços recém-criados, um PAE tem o objetivo de regularizar terras para populações tradicionais extrativistas que já viviam há gerações em determinada área. Dessa forma, o assentamento é criado num lugar previamente demarcado por relações sociais já estabelecidas, com suas próprias organizações e redes de reciprocidade; portanto, nos PAEs, não deveria existir o deslocamento de famílias (THOMAS et al., 2014).

Os PAEs são uma variante das reservas extrativistas, incialmente criadas para resolver conflitos territoriais sofridos pelos seringueiros. Foram criados no governo de Fernando Henrique Cardoso (FHC), entre os anos de 1995 e 2002, resultado de inúmeras ações e pressões de movimentos sociais e seringalistas liderados por Chico Mendes, os quais reivindicavam novos 
modelos de reforma agrária que privilegiassem o modo de vida das populações tradicionais amazônicas e garantissem seu direito de posse e de acesso aos serviços básicos de saúde, educação e infraestrutura (ALLEGRETTI, 2008). Para este autor, as reservas extrativistas surgiram como conceito em 1985, durante o primeiro Encontro Nacional dos Seringueiros: são áreas públicas, de propriedade da União, não divididas em parcelas individuais, asseguradas para comunidades com tradição no uso dos recursos naturais, mediante regras de uso definidas pelo poder público.

A regularização fundiária, nesse caso, dá-se por titulação coletiva, em que as associações das comunidades e federação são os representantes das famílias assentadas. No caso do PAE Eixo Forte, trata-se de um assentamento consolidado coletivo, ou seja, na teoria, possui um único lote com reserva legal coletiva definida e demarcações individuais imaginárias ou sob o acordo de vizinhança. No entanto a política fundiária que é exercida dentro do assentamento não segue tais parâmetros, como veremos a seguir (EMATER, 2011).

\subsection{Assentamento agroextrativista como direito coletivo}

Importante destacar que, para esse tipo de assentamento, o INCRA é responsável por receber requerimento para criação de um PAE, bem como realiza o levantamento da situação socioeconômica das famílias e demarca a terra; e, caso entre essas terras existam áreas de propriedades particulares, elas serão desapropriadas (INCRA, 1996a).

De forma geral, o INCRA recebe inscrições, cadastra e realiza a seleção de candidatos a beneficiários do Programa Nacional de Reforma Agrária. A partir disso, será formado um banco de dados com informações sobre os candidatos a beneficiários de lotes em assentamentos e, assim, de acordo com os critérios de classificação, a equipe dessa instituição determina quais famílias têm prioridade de ser assentadas nos imóveis rurais. Os critérios para a classificação das famílias cadastradas levam em consideração: tamanho da família; força de trabalho da família; idade do candidato; tempo de atividade agrícola; moradia no imóvel desapropriado; moradia no município; tempo de residência no imóvel e a renda anual familiar. Contudo somente 
o cadastro não dá garantia de que o candidato receberá de fato a terra, não dá direito de ser assentado, mas a inscrição e o cadastro identificam a real demanda quantificada por terra no Brasil (INCRA, 2018).

Após classificação e conforme a capacidade do assentamento, é feita a homologação (ato formal de aprovação do candidato) dos nomes dos candidatos, os quais são divulgados em um documento designado por Relação de Beneficiários (RB). Os moradores assentados devem se organizar em associação, dando forma às associações comunitárias. No caso das comunidades que formam o Eixo Forte, a união dessas organizações formou a federação, a qual representa todo o assentamento agroextrativista (EMATER, 2008). Nesse sentido, ressalta-se que, nos PAEs, os beneficiários não possuem título individual, e sim coletivo da área do assentamento, portanto o direito de posse é de todos e passa de pai para filho, de geração a geração, por direito adquirido (EMATER, 2011).

Tais imóveis, enquanto bens, podem ser analisados a partir da Constituição Federativa do Brasil de 1988, em seu art. 20, que estabelece quais os bens da União, e como a natureza jurídica e a dominialidade fundamentam a elaboração de mecanismos de proteção e uso desses bens, com regras estabelecidas para o manejo dos recursos naturais dessas áreas federais (BRASIL, 1988). Quando considerados bens públicos, a Lei $n$. 10.406/2002 (Código Civil Brasileiro de 2002), no seu art. 99, classifica-os como: os de uso comum do povo, tais como rios, mares, estradas, ruas e praças; os de uso especial, edifícios ou terrenos destinados ao serviço ou estabelecimento da administração federal, estadual, territorial ou municipal; e os dominicais, que constituem patrimônio das pessoas jurídicas de direito público, como objeto de direito pessoal ou real, de cada uma dessas entidades (BRASIL, 2002).

Para Di Pietro (2006), o uso comum dos bens públicos pode ser com gratuidade ou retribuído conforme lei específica que estabeleça as regras, podendo ser utilizados por qualquer indivíduo (sujeito) em igualdade de condições com os demais membros da sociedade, ou, na exceção, podendo ser usado por particulares com exclusividade. Os instrumentos estatais que outorgam esse uso privativo do bem comum são: autorização, permissão e concessão. Assim, entidade representativa do Assentamento Agroextrativista 
Eixo Forte é responsável pelas terras, por meio do instrumento de Concessão de Direito Real de Uso (CDRU). Esse instrumento constitui em um direito real e somente é efetivado em caso de interesse social (UCHOA, 2016); no caso do Eixo Forte, interessa em assentar e regularizar a situação de várias famílias de agroextrativistas, bem como salvaguardar o ambiente dessa área.

Carvalho et al. (2013) trataram esse instrumento, de acordo com o contexto agrário, como sendo um documento utilizado pelo Poder Público para "permitir a uma família beneficiária de terras pela reforma agrária os direitos de uso de uma terra e seus recursos naturais". Por outro lado, conforme Brasil (1967), no âmbito federal, a CDRU é vista como garantia ao morador com direito real sobre o imóvel em áreas urbanas, sob a anuência do Poder Legislativo para a concessão do terreno (área). Em se tratando de regularização fundiária, como o caso do PAE Eixo Forte, esse instrumento tem importante papel, protegendo o beneficiário contra qualquer pessoa que queira violar ou prejudicar o direito de posse, de utilizar ou dispor do imóvel.

Pelo CDRU, o INCRA transfere o uso da terra pública ao particular, com direito real resolúvel para que dele se utilize em fins específicos de uso, industrialização, edificação, cultivo ou qualquer outra exploração de interesse social (COSTA, 2002). Nesse sentido, para o uso do imóvel concedido aos assentados, faz-se necessário consolidar o assentamento desde sua criação até a operação. Para tanto, Alencar et al. (2016, p. 34-7) ressaltam que a idade do assentamento é determinada pela data de sua criação e representa uma informação fundamental para o entendimento do processo de desenvolvimento socioeconômico e ambiental e das fases de consolidação do assentamento. Para estes autores, trata-se de importantes indicadores de impacto da política de reforma agrária para a fixação do homem no campo e melhoria da qualidade de vida das famílias assentadas.

Um PAE contribui também para a existência de um lugar para comercialização da produção, marcado por relações sociais já estabelecidas, redes de reciprocidade e afinidade já vigentes e que têm se explicitado na própria organização e distribuição das residências, bem como nas formas de ocupação de espaço (SILVEIRA; WIGGERS, 2013). Essa modalidade de assentamento, surgida como proposta de regularização fundiária para 
populações tradicionais agroextrativistas que mantenham uma relação conservacionista e preservacionista com os recursos naturais (INCRA, 1996a), foi a mais aplicada na região amazônica. O PAE visa à regularização fundiária de terras, tem como público-alvo as populações extrativistas e comunidades tradicionais, as quais usam o modo agroextrativista para sobreviver, seja em terra firme, seja em várzea, populações autóctones que já utilizavam a floresta para sua subsistência e, por isso, podem ser encontradas nos estados do Acre, Amazonas, Pará e Amapá.

Para Le Tourneau e Bursztyn (2010), a Amazônia, com menos de $15 \%$ da população rural do país, abriga quase $55 \%$ dos lotes distribuídos pelo INCRA, o que torna manifesto que o Estado brasileiro vem adotando a implantação de projetos de assentamento largamente nessa região. Consideram ainda que a terceira fase de colonização, com a criação dos projetos de assentamentos diferenciados, marca, a partir de 2006, a implantação dos PAEs na região do Baixo Amazonas no Pará, visto que, até o ano de 2004, não há registros de criação de projetos nessa modalidade no Estado do Pará e na Amazônia Legal.

\subsection{Marco legal pertinente aos PAEs}

A lei que regulamenta regras para a reforma agrária, de cunho federal, trata também da política de reforma agrária e prevê a utilização de terras rurais da União para fins de reforma agrária, almejando-se eliminar a concentração fundiária e viabilizando condições dignas para a vida do trabalhador rural (BRASIL, 1993). Com relação ao PAE Eixo Forte em Santarém, objeto de estudo desta pesquisa, esse foi criado por legislação específica interna do INCRA e amparada em outras normas legais vigentes e pertinentes.

Para o entendimento da criação do PAE Eixo Forte, podem ser considerados alguns fundamentos legais que alicerçaram a base da criação em lei dos projetos de assentamentos extrativistas e, posteriormente, dos agroextrativistas com viés de preservação e conservação ambiental, tomando-se por base das legislações mais antigas, pois todas contribuíram de forma significativa ao perfil estabelecido para os assentamentos diferenciados (INCRA, 1996b). Dessa forma, a importância das atividades extrativistas e 
agroextrativistas tem cunho econômico rural, de transformações de atividades sustentáveis, como também pela promoção do desenvolvimento sustentável, previsto na norma legal de criação da modalidade PAE (INCRA, 1996a). Conforme o Estatuto da Terra (Lei n. 4.504/1964), a política agrícola brasileira pode ser entendida como "[...] o conjunto de providências de amparo à propriedade da terra, que se destina a orientar, no interesse da economia rural, seja no sentido de garantir-Ihes o pleno emprego, seja no de harmonizá-las com o processo de industrialização do país" (BRASIL, 1964), adotando uma interpretação específica para o termo agrícola, que indica a política destinada a amparar o produtor rural.

No que diz respeito aos projetos de assentamentos agroextrativistas, bem como o PAE Eixo Forte, o Estatuto da Terra (BRASIL, 1964) traz ainda o termo "função social da propriedade" como direito fundamental, conforme dito alhures, aplicável à propriedade rural por ser norma específica. De acordo com essa lei, é assegurada a todos a oportunidade de acesso à propriedade da terra, devendo ser utilizada/manejada dentro do conceito de função social ou socioambiental de propriedade, isto é, intimamente relacionada à conservação dos recursos naturais, assegurando aspectos ambientais protetivos para a terra, a família e os recursos naturais, tudo na forma prevista em lei. Por isso, alguns fundamentos têm base nos princípios fundamentais que norteiam os direitos individuais dos assentados na lei máxima brasileira, consolidados pelo princípio da dignidade da pessoa humana, sendo que nos incisos XXII e XIII do artigo 5o da Constituição Federativa do Brasil de 1988, está descrito sobre a garantia do direito de propriedade (em sua acepção moderna, não só na forma individual, mas coletiva e solidária) e do cumprimento de sua função social, combinados com o art. 1.228 do Código Civil (BRASIL, 2002) e arts. 170 e 186 da Constituição Federativa do Brasil de 1988 (BRASIL, 1988), direcionados à política agrícola e fundiária.

Após a Constituição Federal de 1988, a partir de seu capítulo reservado à reforma agrária, que historicamente foi uma bandeira dos movimentos sociais do campo, em 1993 o governo federal propôs a Lei da Desapropriação por interesse social, Lei n. 8.629/1993, marcando o início da terceira fase da Reforma Agrária no Brasil, a qual apresentou relevante importância para a criação dos assentamentos diferenciados, tais como os PAEs (ALENCAR et al., 
2016). Até os anos de 1988, os projetos de assentamentos convencionais já haviam migrado da lógica do discurso da colonização dos territórios na Amazônia, como era pregado na época do governo militar no Brasil, para uma lógica de apoio à produção do campo e de redistribuição de terras (ALENCAR et al., 2016). Ademais, adequando-se ao ordenamento jurídico vigente, em especial à Constituição Federal de 1988, o Código Civil do Brasil (Lei n. 10.406/2002) estabeleceu no $\$ 1$ ㅇ, do art. 1228, que o direito de propriedade deve ser exercido em consonância com suas finalidades econômicas e sociais, de modo que sejam preservados, em conformidade com o estabelecido em lei especial, a flora, a fauna, as belezas naturais, o equilíbrio ecológico e o patrimônio histórico e artístico, bem como evitada a poluição do ar e das águas (BRASIL, 2002). Fundamenta-se, então, o exercício da sustentabilidade, sobre preceitos qualitativos de melhoria de vida.

Para regulamentar a posse de terras dos povos e das comunidades que já ocupavam tradicionalmente suas áreas, criou-se por normativa os Projetos de Assentamentos Agroextrativistas, pelas portarias do INCRA n. $627 / 1987$ e n. 268/1996. A segunda alterou a criação da modalidade de assentamentos diferenciados, surgindo a modalidade de assentamento agroextrativista em substituição ao assentamento extrativista (INCRA, 1996a), sendo aprovada a metodologia para implantação desses projetos de base agroextrativista pela Portaria n. 269/1996 (INCRA, 1996b). À luz da legislação agrária pertinente, leia-se a Portaria n. 268/1996, ficou estabelecido que o PAE é uma modalidade de assentamento destinado às populações tradicionais, para exploração de riquezas extrativistas, por meio de atividades economicamente viáveis e ecologicamente sustentáveis (INCRA, 1996a).

Essa modalidade de regularização fundiária atinge também extrativistas e ribeirinhos, em áreas em que são usadas as florestas para sua sobrevivência; ressalta o limite de respeito e áreas coletivas; fomenta a organização por Associação Comunitária; prevê proibição de vendas das áreas no mercado de terras; exige a criação de um Plano de Utilização (PU) do assentamento e de um Plano de Desenvolvimento do Assentamento (PDA) (EMATER, 2008).

O PAE pode ser criado legalmente nas terras da União (em nível federal), sendo responsabilidade dela, por meio do INCRA, como gestor fundiário, a 
obtenção da terra, sua criação e seleção dos beneficiários; também, em terra dos Estados (em nível estadual), tendo sua criação e gestão realizada no Pará pelo Instituto de Terras do Pará (ITERPA) (recebe o nome PEAEX); e em áreas de várzea e ilhas, podendo beneficiar famílias que vivem dos recursos naturais, tais como florestas, peixes, animais silvestres e outros, de modo que exerçam atividades com viabilidade social e econômica e sustentabilidade ambiental (ALENCAR et al., 2016). Por meio da Instrução Normativa n. 15, de 30 de março de 2004, o INCRA dispôs do processo de implantação e desenvolvimento de projetos de assentamentos da reforma agrária, articulando e integrando políticas públicas de assistência técnica, extensão rural, educação, saúde, cultura, eletrificação rural e saneamento básico necessários ao desenvolvimento do projeto de assentamento (INCRA, 2004).

No PAE, os beneficiários em geral são originados de comunidades extrativistas que já habitavam a região demarcada há gerações. Os benefícios decorrentes da reforma agrária e a concessão de uso da terra são aspectos que os assentados recebem mediante caracterização e preenchimento de requisitos que instituem o perfil de cliente da reforma agrária, segundo dispõe a Lei n. 8.629/1993 (Lei Agrária), quando prevê que o título de domínio e a concessão de uso serão conferidos ao homem ou à mulher, ou a ambos, independentemente de estado civil, observada a ordem preferencial, elencados em seus incisos subsequentes (BRASIL, 1993). Os beneficiários da reforma agrária podem ser os agricultores e agricultoras, adultos ou emancipados, que sejam sem-terra; posseiro, assalariado, parceiro ou arrendatário; e aquele cuja propriedade não seja maior que um módulo rural do município (INCRA, 2018), medida que pode representar até 110 hectares em algumas áreas da Amazônia brasileira e, em Santarém, equivale a 75 hectares.

Cumpre destacar que o INCRA prevê ainda o perfil de quem não pode ser assentado, no qual são excluídos: funcionário público federal, estadual ou municipal - a regra se aplica também ao cônjuge ou parceiro; candidato com renda familiar proveniente de atividade não agrícola, superior a três salários mínimos mensais; agricultor que for dono, sócio ou cotista de empresa ou indústria - a proibição se aplica, ainda, a cônjuge ou companheiro; qualquer pessoa que já foi assentada anteriormente - regra vale para o cônjuge ou 
companheiro; estrangeiro não naturalizado; aposentado por invalidez - não se aplica a cônjuge ou parceiro; condenado pela Justiça (por sentença final definitiva transitado em julgado), com pena pendente de cumprimento ou não prescrita etc. (INCRA, 2018).

As condições exigidas acima são válidas apenas para o ato do cadastro. As regras para o trabalhador rural já assentado são aquelas constantes no verso do Contrato de Concessão de Uso (CCU), que é a titulação de responsabilidade da União. Os procedimentos para inscrição e seleção de candidatos são regidos pela Norma de Execução do INCRA n. 45/2005 (INCRA, 2005b) e Norma de Execução INCRA n. 116/2016 (INCRA, 2016), e legislação vigente. Dito isso, consoante Silva (2001), a condição de cláusula pétrea e de aplicação imediata da funcionalidade social é um "dever-coletivo", em que a propriedade só passa a estar garantida com o cumprimento daquela, e afirma que o direito à propriedade não foi restringido, aliás, continua próprio do indivíduo. A função social passou também a ser um fundamento básico, e o interesse individual deve ser submetido ao bem-estar geral.

\subsection{A função socioambiental e o PAE Eixo Forte}

Locke (1978) dizia que o Estado surgiu para proteger a propriedade e regular o direito a ela, já que, antes, no chamado estado de natureza, muitos conflitos ocorreriam por falta de regras e delimitações; para Rousseau, contudo, os problemas da humanidade teriam começado justamente quando alguém resolveu demarcar um pedaço de terra e chamá-lo de seu, portanto somente evidenciam os problemas evidentes ligados à posse e à distribuição de terra (BRANDÃO, 2009). Para esses autores, a tendência no Brasil é a concentração de grandes áreas nas mãos de poucos, dos detentores de recursos ou dos que têm fácil acesso. O que é preocupante, na medida em que pequenos proprietários ou posseiros, sem ter condições necessárias ao cultivo, abandonam ou vendem seus lotes e, com isso, tem-se o surgimento dos movimentos sociais dos sem-terra e outros similares, em que muitos despossuídos de vínculo com o meio rural, desempregados ou subempregados, vão à procura de local para se fixar e acabam por cometer invasões de prédios públicos e de fazendas produtivas. 
A função social da propriedade é uma das grandes conquistas do ordenamento jurídico brasileiro, em que, mais tarde, o legislador alcança o aspecto ambiental como forma de garantir o uso dos recursos naturais, aliado à preservação e conservação do meio ambiente (BRASIL, 1964). O PAE Eixo Forte, segundo a legislação, deve cumprir também sua função socioambiental, com o entendimento iniciado pela função social da terra (SILVA, 2001), que não significa a limitação do direito de propriedade, mas constitui "poder-dever do proprietário, ou seja, dever positivo do proprietário, que é de dar à propriedade destino determinado e dar-lhe uma função determinada". Pelo Estatuto da Terra (Lei n. 4.504/1964), também aplicável à propriedade rural por ser norma específica, de acordo com o art. 20 (BRASIL, 1964), ao PAE Eixo Forte é assegurada a todos a oportunidade de acesso à propriedade da terra, condicionada pela sua função social, na forma prevista nessa lei. Além disso, a lei definiu dois instrumentos para a promoção da reforma agrária: a desapropriação do latifúndio improdutivo e a tributação progressiva da terra, confirmando desta feita o princípio fundamental da função social da propriedade, visando proteger os recursos naturais da exploração econômica e gerar bem-estar social a proprietários de terras e trabalhadores (BRASIL, 1964). Ademais, de acordo com o que preconizou Benjamin (1993), compreende-se e deve-se levar em consideração a compatibilização dos interesses da coletividade e dos particulares, de forma a assegurar a proteção do ambiente e o cumprimento da função social da propriedade inserida nas políticas públicas de reforma agrária, permitindo a aplicabilidade dos princípios constitucionais de garantia do direito de propriedade e preservação do ambiente como pontos estratégicos de se chegar à sustentabilidade.

O instituto da propriedade da terra surgiu com o desenvolvimento da agricultura e da domesticação de animais, a priori, sendo coletiva e não importando o bem em si, mas tão somente os frutos por ele produzidos, por isso Marés (2003, p. 23) ensina que "A terra não era objeto de propriedade excludente, mas sim as coisas produzidas pelo ser humano ou por ele colhidas. A terra como objeto de direito de propriedade independente de criação ou uso é criação do capitalismo". O autor destacou, ainda, que a função socioambiental da propriedade rural está relacionada às propriedades rurais 
que, mesmo sendo de domínio público, são administradas pelas unidades familiares. Assim como no PAE Eixo Forte, cada assentado tem seu lote por concessão de direito real de uso, isto é, o assentado tem o direito provisório sobre a terra, trabalha na terra, mas a propriedade não está a serviço exclusivo do proprietário, o qual deve desempenhar integralmente sua função social e ambiental, devendo o assentado explorar seu lote atendendo à proteção e conservação do meio ambiente, como interesse da coletividade (SOARES, 2017).

Quanto ao PAE Eixo Forte, esse assentamento tem como aspecto principal o uso da propriedade rural com racionalidade ante a exploração dos recursos naturais e a função socioambiental da propriedade, que tutela o bem ambiental e difuso - o ambiente (INCRA, 1996b). Contudo o assentado e seu comportamento definirão o cumprimento dessa função da propriedade. O beneficiário deve cuidar da terra, mas não poderá dispor dela de forma absoluta e ilimitada, tendo o objetivo de não somente manter sua finalidade social como também a ambiental, de forma a assegurar a perpetuação dos recursos naturais, visando aos interesses das presentes e futuras gerações (INCRA, 2018).

A incorporação do princípio da função socioambiental da propriedade no ordenamento jurídico brasileiro se deu pela Lei n. 4.504/64, denominada "Estatuto da Terra", a qual constituiu um marco regulatório no disciplinamento das relações jurídicas agrárias no país, já que, até então, contava-se somente com a Lei de Terras de 1850 (BRASIL, 1964). Mas a Constituição Federal Brasileira de 1988 inseriu também os elementos que perfazem a função socioambiental da propriedade rural, incluindo-os nos incisos do art. 186, a conferir o inciso II, que trata da utilização adequada dos recursos naturais disponíveis e conservação do meio ambiente. Assim, a Carta Magna promoveu a conciliação do progresso econômico pelo uso dos recursos naturais disponíveis, como o uso da terra, água, floresta etc., em consonância com a proteção equilibrada do meio ambiente, conquanto os aspectos econômico, social e ambiental devem estar intensamente ligados entre si, em benefício do homem e do ambiente, delineando, assim, o cumprimento da função socioambiental e econômica da propriedade (BRASIL, 1988). 
O princípio da função social foi desenvolvido pelo filósofo Leon Duguit (1859-1928), inspirado pelo positivismo de Augusto Comte (1798-1857), para ser aplicado não somente à propriedade, mas também ao indivíduo. Nesse sentido, Figueiredo (2004) assevera que

O proprietário, pelo fato de possuir uma riqueza, deve cumprir uma função social. Seus direitos de proprietário só estarão protegidos se ele cultivar a terra ou não permitir a ruína de sua casa. Caso contrário, será legítima a intervenção dos governantes no sentido de obrigarem o cumprimento, do proprietário, de sua função social (FIGUEIREDO, p. 70, 2004)

Portanto o cumprimento da função socioambiental da propriedade no meio rural deve se efetivar sob os princípios do desenvolvimento sustentável, vez que são necessárias atitudes e ações de sensibilidade e consciência ambiental. Com isso, o princípio não objetiva impedir o desenvolvimento econômico, mas que as atividades sejam desenvolvidas lançando-se mão de instrumentos adequados para a menor degradação possível (FIORILLO, 2006, p. 45).

Benjamin (1993, p. 55) apontou para uma trindade de deveres em que se estrutura a função ambiental da propriedade: "[...] o dever de defender, o dever de reparar e o dever de preservar, esse último conceito amplo que traz para o cidadão uma proibição (não poluir) e uma obrigação positiva (impedir o poluir alheio)". Essa trindade serve de modelo para compreender a extensão da função ambiental da propriedade que não se restringe à simples conduta de preservar. Para o autor, a responsabilidade do assentado, de manter essa relação complexa e até mesmo jurídica com a terra e os recursos naturais, ultrapassa seu direito subjetivo de propriedade, o qual se expressa por meio dos poderes de gozar, fruir e dispor do bem imóvel, e adentra os direitos coletivos de preservar e conservar os recursos naturais, tutelando o bem ambiental e o meio ambiente.

Quando o proprietário não cumpre com a função socioambiental de sua propriedade, muito embora tenha garantido seu direito de propriedade, podem ocorrer intervenções estatais, como as desapropriações e as limitações administrativas. Assim, Meirelles (2012) entende que poderá o proprietário perder seu lote no assentamento, observando-se os preceitos legais, 
por meio do instituto da desapropriação, sem prejuízo das sanções de natureza civil, penal e administrativa decorrentes da observância da legislação protetiva do meio ambiente. E também destaca: "Entende-se por intervenção na propriedade privada todo ato do Poder Público que, fundado em lei, compulsoriamente retira ou restringe direitos dominiais privados ou sujeita o uso de bens particulares a uma destinação de interesse público" (MEIRELLES, 2012, p. 663). Di Pietro (1999) afirmou que existem espécies relevantes de intervenções que podem ser empregadas em situações que envolvam casos concretos, como as desapropriações pelas quais o Estado obriga o particular a transferir seu bem, e as limitações administrativas que, enquanto disposições gerais, se ajustam aos direitos dos proprietários, sem promover a transferência do domínio.

\section{CONSIDERAÇÕES FINAIS}

O panorama retratado neste trabalho permite compreender como a legislação amparou a criação do PAE Eixo Forte e os aspectos que motivaram sua implantação, concebida sob características marcantes em prol da preservação e conservação dos recursos naturais e da função socioambiental do imóvel rural.

Diante do que foi estudado, pode-se inferir que a região do Eixo Forte tem, em suas comunidades mais antigas fundadas, o alicerce de que em toda aquela região já havia presença de famílias há séculos, com seus próprios modos de vida e costumes. Com o passar dos tempos, as dificuldades de infraestrutura e serviços nessa região motivaram e alimentaram o movimento catequético e da união dos comunitários a desenvolver trabalhos conjuntos para a melhoria de vida de todos, e nesse ensejo conseguiram que o INCRA criasse o PAE Eixo Forte. A criação levou em consideração o acervo ambiental bastante significativo na área e por haver presença de agricultores familiares e extrativistas na região, que tinham o perfil para assentados na modalidade de agroextrativismo. Com a criação, vieram os benefícios de infraestrutura viária, escolas, posto de saúde, comércio e outros.

Uma das grandes vantagens da criação e regularização desse território foi a de que as famílias dos beneficiários, isto é, os assentados, teriam 
a garantia de uso sustentável dos recursos naturais dessa região, que é assegurada quando os assentados utilizam as terras do assentamento sob os princípios do desenvolvimento sustentável, mesmo que o crescimento urbano venha sendo uma ameaça a esse território. Nesse contexto, o assentamento foi criado dentro de uma legislação específica, devendo seguir regras das políticas agrárias e fundiárias, inclusive conciliando com a área ambiental, visto que uma de suas características é a preservação e conservação dos recursos naturais existentes em seus limites estabelecidos.

Finalmente, os assentados devem cumprir a sua função socioambiental da propriedade rural, conforme preceituam as normas vigentes, no âmbito tanto das esferas agrárias como ambientais. Para isso, espera-se que as políticas públicas e outras intervenções do Estado contribuam para esse cumprimento.

\section{REFERÊNCIAS}

ALENCAR, A.; PEREIRA, C.; CASTRO, I.; CARDOSO, A.; SOUZA, L.; COSTA, R.; BENTES, A. J.; STELLA, O.; AZEVEDO, A.; GOMES, J.; NOVAES, R. Desmatamento nos assentamentos da Amazônia: histórico, tendências e oportunidades. Brasília: IPAM, 2016. Disponível em: https://ipam.org.br/wp-content/uploads/2016/02/Desmatamento-nosAssentamentos-da-Amaz\%C3\%B4nia.pdf. Acesso em: 18 nov.2018.

ALLEGRETTI, M. A construção social de políticas públicas - Chico Mendes e o movimento dos seringueiros. Desenvolvimento e Meio Ambiente, Curitiba, v. 18, n. 2, p. 39-59, 2008. doi: http://dx.doi.org/10.5380/dma.v18i0.13423

BARBOSA, J. M. A. O mapa geral do bispado e a divisão política da província do Grão-Pará em 1759. Revista do Tribunal de Contas do Estado do Pará, Belém, v. 6, n. 8, p. 219-40, 1976.

BENJAMIN, A, H. V. Função Ambiental. In: BENJAMIN, A. H. V. (Org.). Dano Ambiental: prevenção, reparação e repressão. São Paulo: Revista dos Tribunais, 1993.

BRANDÃO, L. C. K. A Colonização Brasileira, do descobrimento ao estatuto da Terra. Planeta Amazônia: Revista Internacional de Direito Ambiental e Políticas Públicas, Macapá, v. 9, n. 1, p. 1-26, 2009.

BRASIL. Lei 10.406, de 10 de janeiro de 2002. Institui o Código Civil. Brasília-DF, 2002. 
BRASIL. Lei n. 9.985, de 18 de julho de 2000. Regulamenta o art. 225, § 1으, incisos I, II, III e VII da Constituição Federal, institui o Sistema Nacional de Unidades de Conservação da Natureza e dá outras providências. Brasília-DF, 2000.

BRASIL. Lei n. 8.629, de 25 de fevereiro de 1993. Dispõe sobre a regulamentação dos dispositivos constitucionais relativos à reforma agrária, previstos no Capítulo III, Título VII, da Constituição Federal. Brasília-DF, 1993.

BRASIL. Congresso Nacional. Constituição da República Federativa do Brasil de 1988, de 5 de outubro de 1988. Brasília-DF,1988.

BRASIL. Decreto lei $n$. 271, de 28 de fevereiro de 1967. Dispõe sobre loteamento urbano, responsabilidade do loteador, concessão de uso e espaço aéreo e dá outras providências. Brasília-DF: 1967.

BRASIL. Lei n. 4.504, de 30 de novembro de 1964. Dispõe sobre o estatuto da Terra e dá outras providências. Brasília-DF: 1964.

CARVALHO, K. O.; TRECANNI, G. D.; EHRINGHAUS, C.; VIEIRA, P. A.; OLIVEIRA, T. I.; GARANTIZADO, S. M. Trilhas da regularização fundiária para comunidades nas florestas amazônicas: como decidir qual a melhor solução para regularizar sua terra? Brasília: Imazon/Cifor/Fase/IEB, 2013.

COSTA, F. C. V. Concessão de Direito Real de Uso (CDRU). In: ALFONSIN, B. M.; SERPA, C. B. de; FERNANDES, E.; COSTA, F. C. V. da; GRAZIA, G. de; SAULE JUNIOR, N.; LEÃO JUNIOR, P. S. M.; ROLNIK, R. (Coord.) Regularização da terra e da moradia: o que é e como implementar. São Paulo: Instituto Pólis, p. 114-18, 2002. Disponível em: https://www.suelourbano.org/wp-content/uploads/2017/09/CartilhaREGULARIZA\%C3\%87\%C3\%830-DA-TERRA-E-DA-MORADIA-O-QUE-\%C3\%89-ECOMO-IMPLEMENTAR.pdf. Acesso em: 4 ago. 2018.

DI PIETRO, M. S. Z. Direito Administrativo. 19. ed. São Paulo: Atlas, 2006.

DI PIETRO, M. S. Z. Direito administrativo. 10. ed. São Paulo: Atlas, 1999.

EMPRESA DE ASSISTÊNCIA TÉCNICA E EXTENSÃO DO ESTADO DO PARÁ [EMATER]. Plano de Utilização do Projeto de Assentamento Agroextrativista do Eixo Forte PU. Santarém: Emater, 2011.

EMPRESA DE ASSISTÊNCIA TÉCNICA E EXTENSÃO DO ESTADO DO PARÁ [EMATER]. Plano de Desenvolvimento do Projeto de Assentamento Agroextrativista do Eixo Forte. Santarém: Emater, 2008. 
FIGUEIREDO, G. J. P. A propriedade no Direito Ambiental. Rio de Janeiro: ADCOAS, 2004.

FIORILLO, C. A. P. Curso de Direito Ambiental Brasileiro. 7. ed. São Paulo: Saraiva, 2006.

GERHARDT, T. E.; SILVEIRA, D. T. Métodos de pesquisa. Porto Alegre: Editora da UFRGS, 2009.

INSTITUTO NACIONAL DE COLONIZAÇÃO E REFORMA AGRÁRIA [INCRA]. AcesSo a Terra. INCRA, Brasília, 2018. Disponível em: http://www.incra.gov.br/acesso-terra. Acesso em: 30 jul. 2018.

INSTITUTO NACIONAL DE COLONIZAÇÃO E REFORMA AGRÁRIA [INCRA]. Relação de Beneficiários. Santarém: INCRA/Sipra, 2017.

INSTITUTO NACIONAL DE COLONIZAÇÃO E REFORMA AGRÁRIA [INCRA]. Norma de Execução INCRA n. 116/2016, de 7 de março de 2016. Altera a Norma de Execução n. 45, de 25 de agosto de 2005, que dispõe sobre procedimentos para seleção de candidatos ao Programa Nacional de Reforma Agrária. Brasília-DF, 2016.

INSTITUTO NACIONAL DE COLONIZAÇÃO E REFORMA AGRÁRIA [INCRA]. Portaria/ INCRA/SR-30/n. 44, de 20 de dezembro de 2005. Dispõe sobre a criação do projeto de Assentamento Agroextrativista do Eixo Forte. Santarém, PA, 2005a.

INSTITUTO NACIONAL DE COLONIZAÇÃO E REFORMA AGRÁRIA [INCRA]. Norma de execução n. 45, de 25 de agosto de 2005. Dispõe sobre procedimentos para seleção de candidatos ao Programa Nacional de Reforma Agrária. Brasília, 2005b.

INSTITUTO NACIONAL DE COLONIZAÇÃO E REFORMA AGRÁRIA [INCRA]. Instrução Normativa n. 15, de 30 de março de 2004. Dispõe sobre o processo de implantação e desenvolvimento de projetos de assentamentos da reforma agrária. Brasília: 2004.

INSTITUTO NACIONAL DE COLONIZAÇÃO E REFORMA AGRÁRIA [INCRA]. Portaria/ INCRA n. 268, de 23 de outubro de 1996. Cria a modalidade de Projeto de Assentamento Agroextrativista. Brasília: 1996a.

INSTITUTO NACIONAL DE COLONIZAÇÃO E REFORMA AGRÁRIA [INCRA]. Portaria/ INCRA n. 269, de 23 de outubro de 1996. Aprova metodologia para implantação de assentamentos de base agroextrativista. Brasília: 1996b. 
LE TOURNEAU, F, M.; BURSZTYN, M. Assentamentos Rurais na Amazônia: contradições entre a política agrária e a política ambiental. Ambiente \& Sociedade, Campinas, v. 13, n. 1, p. 111-30, 2010. doi: http://dx.doi.org/10.1590/ S1414-753X2010000100008

LOCKE, J. Carta acerca da tolerância - segundo tratado sobre o governo: ensaio acerca do entendimento humano. 2. ed. São Paulo: Abril Cultural, 1978.

MACHADO, L. O. Mitos e realidades da Amazônia brasileira no contexto geopolítico internacional (1540-1912). 1989. Tese (Doutorado em Geografia) - Universitat de Barcelona, Barcelona, 1989.

MARÉS, C. F. A função social da terra. Porto Alegre: S. A. Fabris, 2003.

MEIRELLES, H. L. Direito administrativo brasileiro. 38. ed. São Paulo: Malheiros Editores Ltda., 2012.

PENTEADO, I. M. Participação Social no Conselho Gestor da APA Alter do Chão. 2013. Monografia (Graduação em Psicologia) - Universidade Federal do Rio de Janeiro, Rio de Janeiro, RJ, 2013.

PUREZA, E. S. S. Gestão ambiental em assentamentos agroextrativistas: potencialidades e limites - o caso do PAE Ilha do Mutum, Marajó - Pará, Amazônia. 2017. Dissertação (Mestrado em Gestão de Recursos Naturais e Desenvolvimento Local na Amazônia) - Universidade Federal do Pará, PA, Belém, 2017.

REIS, L. G. Produção Monográfica da teoria à prática: o método educar para a pesquisa (MEP). 4. ed. Brasília: Senac, 2012.

RENTE, A. S. G. Áreas de Proteção Ambiental como inspiração para o desenvolvimento sustentável com liberdade: o caso da criação da APA Alter do Chão. 2006. Dissertação (Mestrado em Desenvolvimento, Agricultura e Sociedade) - Universidade Federal Rural do Rio de Janeiro, Rio de Janeiro, RJ, 2006.

SANTARÉM (Cidade). Câmara Municipal. Lei n. 17.771, de 2 de julho de 2003. Cria a Área de Proteção Ambiental de Alter do Chão, no município de Santarém, Estado do Pará, e dá outras providências. Santarém, PA, 2003.

SANTOS, J. G. S. Eixo Forte e sua história escrita por quem conhece e mora na região. Santarém: Book Antiqua, 2018. [Obra não publicada]. 
SÁ-SILVA, J.; ALMEIDA, R. C. D.; GUINDANI, J. F. Pesquisa documental: pistas teóricas e metodológicas. Revista Brasileira de História \& Ciências Sociais, Rio Grande v. 1, p. 1-15, 2009.

SILVA, R. E. L. Função social da propriedade rural: aspectos constitucionais e sociológicos. Revista de Direito Constitucional e Internacional, São Paulo, v. 9, n. 37, p. 259-60, 2001.

SILVEIRA, L. B.; WIGGERS, R. Protegendo a floresta, reconfigurando espaços na Amazônia: o caso do Projeto de Assentamento Extrativista Santa Maria Auxiliadora, Humaitá (AM). Revista de Administração Pública, Rio de Janeiro, v. 47, n. 3, p. 67193, 2013. doi: http://dx.doi.org/10.1590/S0034-76122013000300007

SOARES, M. P. Assentamentos Rurais Sustentáveis na Amazônia. 2017. Dissertação (Mestrado em Direito Ambiental) - Universidade do Estado do Amazonas, Manaus, AM, 2017.

TAVARES, M. G. C. A Formação territorial do espaço paraense: dos fortes à criação de municípios. Acta Geográfica, Boa Vista, v. 2, n. 3, p. 59-83, 2008. doi: http:// dx.doi.org/10.5654/actageo2008.0103.0005

THOMAS, S.; ALMEIDA, O. T.; CASTRO, F.; MCGRATH, D.; PINHEIRO, E.; RIVERO, S. Regulamentação fundiária na Amazônia e projetos agroextrativistas na várzea do baixo amazonas. In: BAHIA, M. C.; NASCIMENTO, D. M. (Ed.). Estado, sistemas produtivos e populações tradicionais. Belém: NAEA/UFPA, 2014.

UCHOA, A. M. R. L. Alienação gratuita de bens imóveis públicos em favor de particulares à luz dos princípios constitucionais da eficiência e da economicidade. Revista Jurídica, Itajaí, v. 3, n. 4, p. 535-67, 2016. doi: http://dx.doi.org/10.6084/ m9.figshare.4667533

VASCONCELOS, L. C. Limites das comunidades rurais do Projeto de Assentamento Agroextrativista Eixo Forte, Santarém, PA, Brasil. [Prestação de serviço técnico para elaboração do mapa]. Santarém, 2019. 
